Check for updates

Cite this: Chem. Sci., 2019, 10, 9859

๑ All publication charges for this article have been paid for by the Royal Society of Chemistry

Received 30th June 2019

Accepted 28th August 2019

DOI: $10.1039 / c 9 s c 03224$ j

rsc.li/chemical-science

\section{An exceptionally stable octacobalt-cluster-based metal-organic framework for enhanced water oxidation catalysis $\uparrow$}

\author{
Ning-Yu Huang, $\dot{t}^{\mathrm{a}}$ Jian-Qiang Shen, $\dot{t}^{\mathrm{ab}} \mathrm{Zi-Ming} \mathrm{Ye},{ }^{\mathrm{a}}$ Wei-Xiong Zhang, $\mathbb{D}^{a}$ \\ Pei-Qin Liao (iD *a and Xiao-Ming Chen (D) ${ }^{*}$
}

\begin{abstract}
Extensive efforts have been devoted to developing efficient and durable catalysts for water oxidation. Herein, we report a highly stable metal-organic framework that shows high catalytic activity and durability for electrically driven (an overpotential of $430 \mathrm{mV}$ at $10 \mathrm{~mA} \mathrm{~cm}{ }^{-2}$ in neutral aqueous solution) and photodriven (a turnover frequency of $16 \mathrm{~s}^{-1}$ and 12000 cycles) water oxidation, representing the best catalyst for water oxidation reported to date. Computational simulation and isotope tracing experiments showed that the $\mu_{4}-\mathrm{OH}$ group of the $\left\{\mathrm{CO}_{8}\left(\mu_{4}-\mathrm{OH}\right)_{6}\right\}$ unit participates in the water oxidation reaction to offer an oxygen vacancy site with near-optimal $\mathrm{OH}^{-}$adsorption energy.
\end{abstract}

\section{Introduction}

The replacement of fossil fuels with hydrogen generated by water splitting is a very attractive solution to the present energy problem. In order to develop a practical technology based on these elements, durable and efficient water oxidation catalysts need to be developed. ${ }^{1,2}$ However, the water oxidation process involves a four-electron process, leading to slow kinetics. ${ }^{3,4}$ For this reason, improving the efficiency of water oxidation catalysts is still a challenging task, despite the considerable achievements that have been made in recent years. ${ }^{5-7}$

The active oxygen species (namely, the $\mathrm{O}^{\bullet}$ radical) has been accepted as the important intermediate for the formation of hydroperoxy $(\mathrm{OOH})$ species and for the subsequent conversion to $\mathrm{O}_{2}$ molecules. ${ }^{8}$ Under alkaline conditions, the $\mathrm{M}-\mathrm{O}^{-}(\mathrm{M}=$ metal) species is generated from the oxidation of the $\mathrm{M}-\mathrm{OH}$ species, enhancing the adsorption energy of the reactant $\mathrm{OH}^{-}$, which might be beneficial to the formation of $* \mathrm{OH}$ for the oxygen evolution reaction (OER) intermediates. However, if $\mathrm{OH}^{-}$binds too strongly, it will occupy available surface sites and poison the reaction. ${ }^{9}$ Therefore, optimizing the $\mathrm{OH}^{-}$adsorption energy to a near-optimal value might be beneficial to accelerate the reaction kinetics. ${ }^{10}$ Obviously, regulating the coordination number of the oxygen atom of $\mathrm{OH}^{-}$could be the most effective

${ }^{a}$ MOE Key Laboratory of Bioinorganic and Synthetic Chemistry, School of Chemistry, Sun Yat-Sen University, Guangzhou 510275, China. E-mail: liaopq3@mail.sysu.edu.cn ${ }^{b}$ Department of Chemical and Biomolecular Engineering, University of California, Los Angeles, CA 90095, USA

$\dagger$ Electronic supplementary information (ESI) available: Experimental details, crystal data and structure refinement results, thermogravimetric analyses, variable-temperature PXRD. CCDC 1881071. For ESI and crystallographic data in CIF or other electronic format see DOI: 10.1039/c9sc03224j

$\$ \mathrm{~N}$.-Y. Huang and J.-Q. Shen contributed equally to this work. strategy to optimize the adsorption energy (Scheme 1). For instance, Jin et al. incorporated gold clusters onto the $\mathrm{CoSe}_{2}$ catalyst to increase the coordination number of the $\mathrm{OH}^{-}$from 1 to 2, resulting in the enhancement of activity. ${ }^{11}$ Nevertheless, the binding affinity was still too weak, leading to a large amount of energy input required to produce ${ }^{*} \mathrm{OH}$.

Metal-organic frameworks (MOFs), as crystalline porous materials with high surface areas and outstanding structural designability, can combine the advantages of both homogeneous and heterogeneous catalysts. Recently, MOFs have emerged as potential catalysts for water oxidation, ${ }^{12,13}$ the hydrogen evolution reaction, ${ }^{\mathbf{1 4 - 1 7}}$ carbon dioxide reduction, ${ }^{\mathbf{1 8 - 2 2}}$ etc. ${ }^{\mathbf{1 4 , 2 3 - 2 5}}$ Nevertheless, as similar to traditional catalysts, the reported MOF catalysts also suffer from poor stability and low catalytic activity. ${ }^{26,27}$ Among the various types of MOFs, metalazolate frameworks (MAFs) are famous for their extraordinary chemical stabilities. ${ }^{28}$ In addition, the high connectivity of the metal cluster could enhance the stability of the framework. ${ }^{29,30}$ Considering the relatively high activities and earth-abundance of cobalt ions, and that the multinuclear metal cluster might have a favourable $\mathrm{OH}^{-}$adsorption energy, a combination of the highly connected cobalt-hydroxide unit and the azolate bridging ligand is the best choice. Here, we report a highly stable, octacobalt cluster based MAF with both extraordinarily

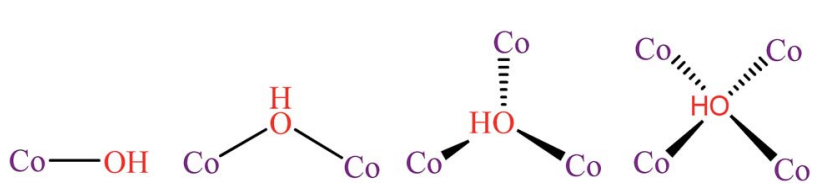

Scheme 1 Proposed models of the reactant hydroxyl ion coordinated to the cobalt ions during the water oxidation reaction. 
high activity and durability. We demonstrated that the metal site, capping four coplanar cobalt ions, indeed serves as a highly efficient active site for water oxidation.

\section{Experimental section}

\section{Materials and methods}

All reagents were commercially available and used without further purification. 1,4-Benzenedi(1H-1,2,3-triazole $\left(\mathrm{H}_{2} \mathrm{bdt}\right)$ was synthesized according to the method in the literature. Elemental analyses (EA) were conducted using an Elementar Vario EL analyzer. X-ray photoelectron spectroscopy (XPS) measurements were performed with a VG Scientific ESCALAB 250 instrument. Powder X-ray diffraction (PXRD) patterns were collected on a Bruker D8-Advance diffractometer with $\mathrm{Cu} \mathrm{K} \alpha$ radiation and a LynxEye detector. Variable-temperature PXRD data were collected on a Rigaku SmartLab X-ray diffractometer (Cu-K $\alpha, \lambda=1.54056 \AA$ ). Thermogravimetric (TG) analyses were performed on a TA Q50 thermogravimetric analyzer under nitrogen gas at a heating rate of $10{ }^{\circ} \mathrm{C} \mathrm{min}^{-1}$. Scanning electron microscope (SEM) images were obtained from an ultra-highresolution electron microscope (FE-SEM, SU8010). Gas sorption isotherms were measured on a Micromeritics ASAP 2020M instrument. Before the sorption experiments, the assynthesized samples were first solvent exchanged with $\mathrm{MeOH}$, and then activated for $12 \mathrm{~h}$ at $150{ }^{\circ} \mathrm{C}$ under vacuum. $\mathrm{N}_{2}$ (99.999\%) was used for all measurements. The temperature was controlled by a liquid nitrogen bath (77 K).

Synthesis of $\left[\mathrm{Co}_{8}(\mathrm{OH})_{4}\left(\mathrm{H}_{2} \mathrm{O}\right)_{2}(\mathrm{bdt})_{6}\right]$ ' guest (denoted as MAF48 or $\mathrm{Co}_{4}$-bdt)

A mixture of $\mathrm{Co}(\mathrm{OAc})_{2} \cdot 4 \mathrm{H}_{2} \mathrm{O}(17.5 \mathrm{mg}, 0.75 \mathrm{mmol}), \mathrm{H}_{2} \mathrm{bdt}$ (10.5 mg, $0.5 \mathrm{mmol}$ ), triethylamine (TEA, $0.2 \mathrm{~mL}), \mathrm{H}_{2} \mathrm{O}(1.0 \mathrm{~mL})$ and $N, N$-diethylacetoacetamide $(\mathrm{DEF}, 4.0 \mathrm{~mL})$ was stirred for 30 minutes in air, transferred to a $100 \mathrm{~mL}$ vial and sealed with a screw cap, heated in an oven at $160{ }^{\circ} \mathrm{C}$ for $72 \mathrm{~h}$, and then cooled to room temperature at a rate of $10{ }^{\circ} \mathrm{C} \mathrm{h}^{-1}$, giving red cubic crystals. The resulting red microcrystalline powders were washed with EtOH three times and then immersed in $1 \mathrm{M} \mathrm{KOH}$ (yield 78\%). EA calc. (\%) for $\left[\mathrm{Co}_{8}(\mathrm{OH})_{6}(\mathrm{bdt})_{4}(\mathrm{Hbdt})_{2}\right] \cdot 12 \mathrm{H}_{2}-$ $\mathrm{O} \cdot 5 \mathrm{MeOH}\left(\mathrm{C}_{65} \mathrm{H}_{88} \mathrm{~N}_{36} \mathrm{Co}_{8} \mathrm{O}_{23}\right): \mathrm{C}, 35.28 ; \mathrm{H}, 4.01 ; \mathrm{N}, 22.79$; found: C 35.44, H 4.02, N 22.91.

\section{Crystal structure determination}

Diffraction data of $\mathbf{C o}_{\mathbf{4}}$-bdt were collected on a Rigaku XtaLAB P300DS-detector diffractometer $(\mathrm{Cu} \mathrm{K \alpha})$. All structures were solved by direct methods and refined with the full-matrix leastsquares technique on $F^{2}$ by the SHELXTL-2014 software package. All non-hydrogen atoms were refined anisotropically. Hydrogen atoms were placed geometrically. The PLATON SQUEEZE treatment was applied, because all guest solvent molecules were extremely disordered and could not be modeled. Detailed structure determination parameters and crystallographic data are given in Table S1. $\dagger$

\section{Results and discussion}

The solvothermal reaction of $\mathrm{Co}(\mathrm{OAc})_{2}$ and $\mathrm{H}_{2}$ bdt in $N, N$ diethylformamide (DEF) afforded red cubic crystals of $\left[\mathrm{Co}_{8}(-\right.$ $\left.\mathrm{OH})_{6}(\mathrm{bdt})_{4}(\mathrm{Hbdt})_{2}\right]$ (MAF-48, Co $\mathbf{o}_{4}$-bdt). Single-crystal X-ray analysis revealed that $\mathbf{C o}_{\mathbf{4}}$-bdt consists of an fcu network constructed of 12-connected $\mathrm{Co}_{8}\left(\mu_{4}-\mathrm{OH}\right)_{6}\left(\mathrm{Rtrz}_{12}\left(\mathrm{Rtrz}^{-}=1,2,3-\right.\right.$ triazolate group) clusters and 2-connected bdt ${ }^{2-}$ ligands (Fig. 1 and Table $\mathrm{S} 1 \dagger)$, and this is isostructural with $\left[\mathrm{Ni}_{8}(\mathrm{OH})_{4}\left(\mathrm{H}_{2}\right.\right.$ $\left.\mathrm{O})_{2}(\text { bdp })_{6}\right]$ ( $\mathbf{N i}_{\mathbf{4}}$-bdp, $\mathrm{H}_{2}$ bdp $=4,4^{\prime}$-benzene-1,4-diylbis $(1 H$-pyrazole $)) .{ }^{31}$ At each face of $\left\{\mathrm{Co}_{8}\left(\mu_{4}-\mathrm{OH}\right)_{6}\right\}$, the hydroxyl anion links four coplanar $\mathrm{Co}^{\mathrm{II}}$ ions in a typical $\mu_{4}$ coordination mode to form a $\left\{\mathrm{Co}_{4}\left(\mu_{4}-\mathrm{OH}\right)\right\}$ unit, which is an underlying catalytic active site for the water oxidation reaction. X-ray photoelectron spectroscopy (XPS) of $\mathbf{C o}_{\mathbf{4}}$-bdt showed that the metal ions are all divalent (Fig. $\mathrm{S} 1 \dagger$ ).

The purity of $\mathbf{C o}_{\mathbf{4}}$-bdt was preliminarily demonstrated by the scanning electron microscopy (SEM) images and transmission electron microscopy (TEM) images (Fig. S2 $\dagger$ ). Thermogravimetric (TG) and powder X-ray diffraction (PXRD) measurements of methanol-exchanged $\mathbf{C o}_{\mathbf{4}}$-bdt indicated that its guest molecules can be removed above $100{ }^{\circ} \mathrm{C}$, and the host framework can be stable up to $300{ }^{\circ} \mathrm{C}$ (Fig. S3 and S4 $\dagger$ ). Moreover, Co $\mathbf{C o}_{4}$-bdt can remain intact in $6 \mathrm{M} \mathrm{KOH}$ (Fig. S5 $\dagger$ ) for at least 3 days, representing the most alkali stable MOF. ${ }^{32,33} \mathrm{~A} \mathrm{~N}_{2}$ sorption isotherm was measured for $\mathrm{Co}_{4}$-bdt at $77 \mathrm{~K}$ (Fig. S6 $\dagger$ ), which shows typical type-I characteristics, with a saturation uptake of $594 \mathrm{~cm}^{3}$ (STP) (a)

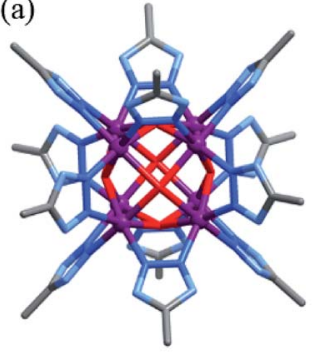

(b)

(c)

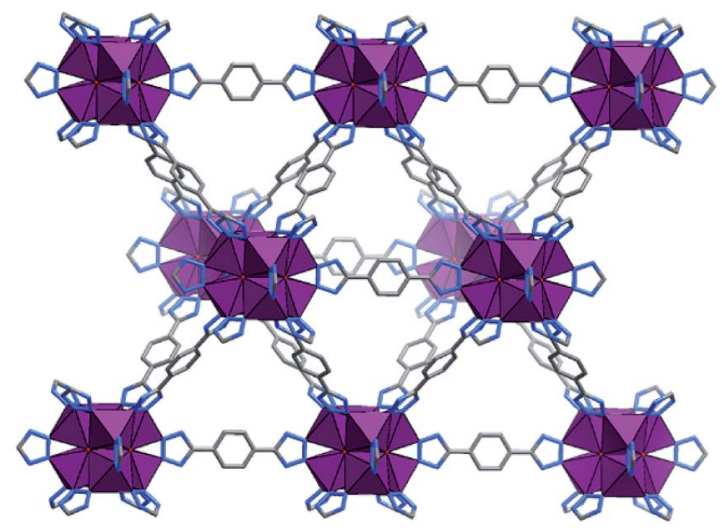

Fig. 1 (a) The $\mathrm{CO}_{8}\left(\mu_{4}-\mathrm{OH}\right)_{6}(\mathrm{Rtrz})_{12}$ cluster (hydrogen atoms are omitted for clarity), (b) the network topology (octanuclear clusters and bistriazolate ligands are simplified as violet polyhedra and blue sticks, respectively), and (c) $3 \mathrm{D}$ coordination framework $\left(\mathrm{CoN}_{3} \mathrm{O}_{3}\right.$ units are shown as violet polyhedra) of $\mathrm{Co}_{4}$-bdt. 
$\mathrm{g}^{-1}$, corresponding to a pore volume of $0.928 \mathrm{~cm}^{3} \mathrm{~g}^{-1}$ (crystallographic value of $0.924 \mathrm{~cm}^{3} \mathrm{~g}^{-1}$ ). Furthermore, the BrunauerEmmett-Teller (BET) and Langmuir surface areas of $\mathbf{C o}_{4}$-bdt were calculated to be 2266 and $2570 \mathrm{~m}^{2} \mathrm{~g}^{-1}$, respectively.

The photodriven water oxidation (PWO) experiment of $\mathbf{C o}_{4^{-}}{ }^{-}$ bdt was performed under visible light in water with $\left[\mathrm{Ru}(\mathrm{bpy})_{3}\right]$ $\mathrm{SO}_{4}$ (bpy $=2,2^{\prime}$-bipyridine) as the photosensitizer and $\mathrm{Na}_{2} \mathrm{~S}_{2} \mathrm{O}_{8}$ as the sacrificial electron acceptor, and these are the typical reaction conditions used in the literature. A Clark-type oxygen electrode was used to monitor in situ the amount of evolved $\mathrm{O}_{2}$ dissolved in the solution (Fig. $2 \mathrm{a}$ and $\mathrm{S} 7 \dagger$ ). $\mathrm{O}_{2}$ rapidly formed at an initial turnover frequency (TOF) of $3.05 \pm 0.03 \mathrm{~s}^{-1}$. Due to the consumption of the sacrificial electron acceptor, the production rates slowly decreased (Fig. S8 $\dagger$ ). Except for PSII, the performance of $\mathbf{C o}_{\mathbf{4}}$-bdt is higher than that for all other known heterogeneous catalysts, ${ }^{26,27,34-39}$ and is comparable to the best homogeneous catalysts under the same conditions ${ }^{40-43}$ (Tables $\mathrm{S} 2$ and $\mathrm{S} 3 \dagger)$. Since the process that limits catalytic turnover is the oxidative quenching of the Ru excited state, ${ }^{4-46}$ the photocatalytic water oxidation experiments using $\left[\mathrm{Ru}(\mathrm{bpy})_{3}\right]^{3+}$ as the chemical oxidant without $\mathrm{Na}_{2} \mathrm{~S}_{2} \mathrm{O}_{8}$ were carried out. It can be seen that the TOF values increased and that the catalysts work under pseudo first order conditions (Fig. S9†). Importantly, the actual TOF value of $\mathbf{C o}_{4}$-bdt is as high as $15.7 \mathrm{~s}^{-1}$ (Fig. S10†), which is higher than that of the best PWO catalyst $\left(13 \mathrm{~s}^{-1}\right) \cdot{ }^{47-50}$

Thanks to the excellent stability, the TOF of $\mathbf{C o}_{4}$-bdt remained $3.05 \mathrm{~s}^{-1}$ (Fig. 2c) after 12000 runs, indicating that the turnover number (TON) is larger than one million. Notably, the TON value of $\mathbf{C o}_{4}$-bdt is two orders higher than that of the best catalysts. ${ }^{51}$ To directly determine the TON of the $\mathbf{C o}_{\mathbf{4}}$-bdt, timedependent oxygen evolution experiments were carried out with chemical oxidant $\left[\mathrm{Ru}(\mathrm{bpy})_{3}\right]^{3+}$. As shown in Fig. S11, $\uparrow \mathbf{C o}_{4}$-bdt gave a TON of $1.2 \times 10^{6}$, which is consistent with that obtained from the recycling experiment (Fig. 2c). After the reactions, the $\mathbf{C o}_{4}$-bdt catalyst was recovered from the reaction mixture and was found to be almost unchanged according to the $\mathrm{N}_{2}$ sorption isotherm measurements (Fig. S6†), the PXRD patterns and the SEM images (Fig. S12†). Furthermore, inductively coupled plasma-mass spectrometry showed that just $0.14 \%$ of the Co ions in $\mathbf{C o}_{4}$-bdt were leached into the reaction solution after the reaction, and the filtrate showed negligible catalytic activity (Fig. S7 $\dagger$ ), which confirmed the heterogeneous nature and the stability of the catalyst. The high stability of $\mathbf{C o}_{\mathbf{4}}$-bdt might be ascribed to the high connectivity of the second building units (SBUs) ${ }^{29}$ and the more stable cobalt-N (nitrogen atom) coordination bonds. ${ }^{28,32}$

In order to study the mechanism, we selected five other cobalt-based MOFs with variable metal-hydroxide units and an isostructural MOF, $\left[\mathrm{Ni}_{8}(\mathrm{OH})_{6}(\mathrm{bdt})_{4}(\mathrm{Hbdt})_{2}\right] \quad\left(\mathbf{N i}_{4}\right.$-bdt $)$, for comparison (Fig. S13-S15†): (i) $\left[\mathrm{Co}_{8}^{\mathrm{II}}\left(\mu_{4}-\mathrm{OH}\right)_{6}(\mathrm{cpt})_{6}\right]\left(\mathbf{C o}_{4}\right.$-cpt, Hcpt $=4$-(4'-carboxyphenyl)-1,2,4-triazole) is made up of octanuclear cobalt-hydroxide $\left\{\mathrm{Co}_{8}\left(\mu_{4}-\mathrm{OH}\right)_{6}\right\}$ clusters and $\mathrm{cpt}^{-}$ ligands; $;^{52}$ (ii) $\left[\mathrm{Co}_{6}\left(\mu_{3}-\mathrm{OH}\right)_{2}(\mathrm{in})_{4}(\mathrm{HCOO})_{6}\right]\left(\mathbf{C o}_{3}\right.$-in, Hin $=$ isonicotinic acid) is made up of asymmetric triangular units of $\left\{\mathrm{Co}_{3}\left(\mu_{3}-\mathrm{OH}\right)\right\}$, in $^{-}$and oxalate ligands. ${ }^{53}$ Each hydroxyl anion is linked to three adjacent $\mathrm{Co}^{\mathrm{II}}$ ions in a typical $\mu_{3}$ coordination mode to build the $\left\{\mathrm{Co}_{3}\left(\mu_{3}-\mathrm{OH}\right)\right\}$ cluster; (iii) $\left[\mathrm{Co}_{2}(\mu-\mathrm{OH})_{2}(\mathrm{bbta})\right]$ $\left(\right.$ MAF-X27-OH/Co $\mathbf{C}_{2}$-bbta, $\mathrm{H}_{2}$ bbta $=1 H, 5 H$-benzo-(1,2- $\left.d: 4,5-d^{\prime}\right)$ bistriazole) bears a pair of $\mu-\mathrm{OH}^{-}$ligands at the cis-positions of its open metal site..$^{32}$ Each hydroxyl anion links two adjacent $\mathrm{Co}^{\mathrm{II}}$ ions in a typical bidentate coordination mode to build a $\left\{\mathrm{Co}_{2}(\mu-\mathrm{OH})\right\}$ unit; (iv) $\left[\mathrm{Co}_{2}\right.$ (dobdc)] (Co-MOF-74/Co-dobdc, $\mathrm{H}_{4}$ dobdc $=2,5$-dihydroxyl-1,4-benzenedicarboxylic acid) is composed of square-pyramidal Co ions and dobdc ${ }^{4-}$ ligands. $^{54}$ The square-pyramidal Co ion can coordinate to a terminal water molecule or to a hydroxyl anion to form a distorted octahedral mode; (v) $\left[\mathrm{Co}(\mathrm{mim})_{2}\right]$ (ZIF-67/Co-mim, Hmim = 2-methylimidazole) is constructed of tetrahedral Co ions and $\mathrm{mim}^{-}$ ligands. ${ }^{55}$ In addition, the tetrahedral Co ion can coordinate to a terminal water molecule or to a hydroxyl anion to form a distorted trigonal-bipyramidal mode.

The PWO experiment was performed under the same conditions. As calculated from the initial $\mathrm{O}_{2}$ production rates (Fig. 2b and S16 $\dagger$ ), the turnover frequency (TOF) for $\mathrm{O}_{2}$ is as follows, $\mathbf{C o}_{4}$-bdt $\left(3.05 \pm 0.03 \mathrm{~s}^{-1}\right) \approx \mathbf{C o}_{4}$-cpt $\left(3.02 \pm 0.05 \mathrm{~s}^{-1}\right)>$ $\mathbf{C o}_{3}$-in $\left(2.37 \pm 0.05 \mathrm{~s}^{-1}\right)>\mathbf{C o}_{2}$-bbta $\left(1.74 \pm 0.03 \mathrm{~s}^{-1}\right)>\mathbf{N i}_{\mathbf{4}}$-bdt $\left(1.21 \pm 0.03 \mathrm{~s}^{-1}\right)>$ Co-dobdc $\left(0.77 \pm 0.03 \mathrm{~s}^{-1}\right) \approx \operatorname{Co}-\mathbf{m i m}(0.58 \pm$ $0.01 \mathrm{~s}^{-1}$ ) (Tables S4 and S5 $\dagger$ ). Interestingly, for the cobalt ions, when the coordination number of the hydroxide ligand increases, the catalytic performance becomes better, and the
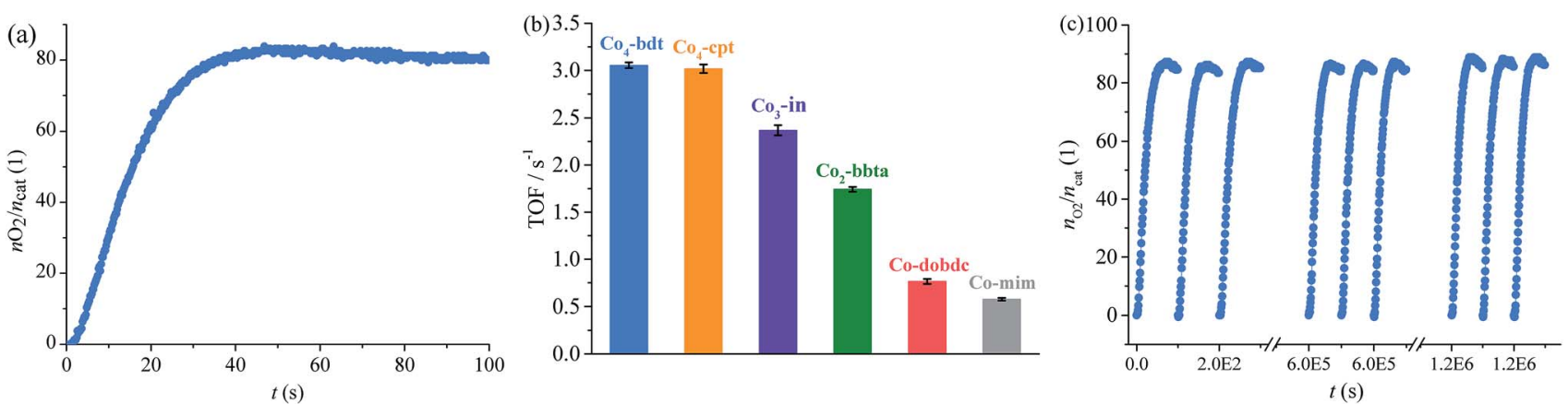

Fig. 2 (a) Kinetics of $\mathrm{O}_{2}$ formation in the photocatalytic system using $\mathrm{Co}_{4}$-bdt as the catalyst. (b) Comparison of the TOF values for the photodriven water oxidation reactions. (c) $\mathrm{O}_{2}$ production profiles of the repeated photocatalytic water oxidation reactions using $\mathrm{Co}_{4}$-bdt as the catalyst. Reaction conditions: $\left[\mathrm{Ru}(\mathrm{bpy})_{3}\right] \mathrm{SO}_{4}(0.03 \mu \mathrm{mol})$, catalyst $(0.5 \mathrm{nmol})$, borate buffer $(\mathrm{pH}=9,2 \mathrm{~mL}), \mathrm{Na}_{2} \mathrm{~S}_{2} \mathrm{O}_{8}(0.1 \mu \mathrm{mol}), \mathrm{LED}$ light $(\lambda=450$ $\pm 5 \mathrm{~nm})$, and $25^{\circ} \mathrm{C}$. 
catalytic performance of $\mathbf{C o}_{\mathbf{4}}$-bdt is much higher than that of $\mathrm{Ni}_{\mathbf{4}}$-bdt.

To demonstrate that the Co-manifold works with a four electron/four proton mechanism, the activity of $\mathbf{C o}_{\mathbf{4}}$-bdt for water oxidation was studied by electrochemical characterization. Linear sweep voltammetry (LSV) was performed in water at

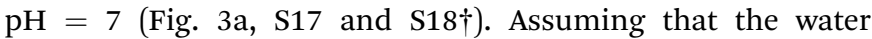
oxidation reaction involves a four-electron process, the Faraday efficiency of $\mathbf{C o}_{\mathbf{4}}$-bdt for water oxidation was measured to be virtually 100\% (Fig. S19 and Table S6†). Importantly, Co $\mathbf{C}_{\mathbf{4}}$-bdt afforded a current density of $2.0 \mathrm{~mA} \mathrm{~cm} \mathrm{~cm}^{-2}$ at an overpotential of $352 \mathrm{mV}$, which is much lower than that for all other reported catalysts (Table S7†). The performance of $\mathbf{C o}_{\mathbf{4}}$-bdt showed negligible changes after OER tests at $10 \mathrm{~mA} \mathrm{~cm}{ }^{-2}$ for $24 \mathrm{~h}$ (Fig. 3b). Furthermore, PXRD patterns (Fig. S12†) and cyclic voltammetry curves (Fig. 3c) of $\mathbf{C o}_{\mathbf{4}}$-bdt showed negligible changes after the electrochemical OER tests for $24 \mathrm{~h}$. The electrocatalytic activity follows the order: $\mathbf{C o}_{\mathbf{4}}$-bdt $(352 \mathrm{mV})>\mathbf{C o}_{\mathbf{4}}$-cpt $(355 \mathrm{mV})>$ Co $_{3}$-in $(385 \mathrm{mV})>$ Co $_{2}$-bbta $(489 \mathrm{mV})>$ Co-dobdc $(544$ $\mathrm{mV})>$ Co-mim $(638 \mathrm{mV})$ (Fig. S17a and Table S7 $\dagger$ ) and this is consistent with results observed from the photodriven water oxidation experiment. This phenomenon demonstrates the high catalytic activity of $\mathbf{C o}_{\mathbf{4}}$-bdt in the water oxidation reaction.

Isotope tracing experiments were carried out to investigate the role of $\mu_{4}-\mathrm{OH}^{-}$during the water oxidation reaction. The extent of ${ }^{18} \mathrm{O}$ catalyst incorporation was calculated to be $c a .44 .8$ $\pm 1.1 \%$, measured by the GC-MS analysis of the acidolyzed sample (Fig. S20 and Table S8†). During a representative water oxidation experiment with ${ }^{18} \mathrm{O}$ labeled $\mathbf{C o}_{\mathbf{4}}$-bdt as the photocatalyst, the photogenerated ${ }^{18} \mathrm{O}^{16} \mathrm{O}(\mathrm{m} / \mathrm{z}=34)$ could be clearly detected, while ${ }^{18} \mathrm{O}^{16} \mathrm{O}$ was not detected in the water oxidation experiment with unlabeled $\mathbf{C o}_{\mathbf{4}}$-bdt (Fig. S21, S22 and Table $\mathrm{S} 9 \dagger)$. After the ${ }^{18} \mathrm{O}$-labeled $\mathbf{C o}_{\mathbf{4}}$-bdt was immersed in $\mathrm{pH}=9$ aqueous solution $\mathrm{H}_{2}{ }^{16} \mathrm{O}$ for $10 \mathrm{~min},{ }^{18 / 16} \mathrm{O}_{2}$ intensity was the same as that of the fresh ${ }^{18} \mathrm{O}$-labeled sample (Fig. S23 $\dagger$ ). This demonstrates that the ${ }^{16} \mathrm{O} /{ }^{18} \mathrm{O}$ exchange behaviour between the water molecule and the cobalt-hydroxide $\left\{\mathrm{Co}_{4}\left(\mu_{4}-\mathrm{OH}\right)\right\}$ unit during the isotope tracing experiment can be neglected for the observed significant ${ }^{18 / 16} \mathrm{O}_{2}$ intensity enhancement. This result indicates that the bridging $\mathrm{OH}^{-}$ligand does indeed participate in the reaction to offer an oxygen vacancy, which serves as the (a)
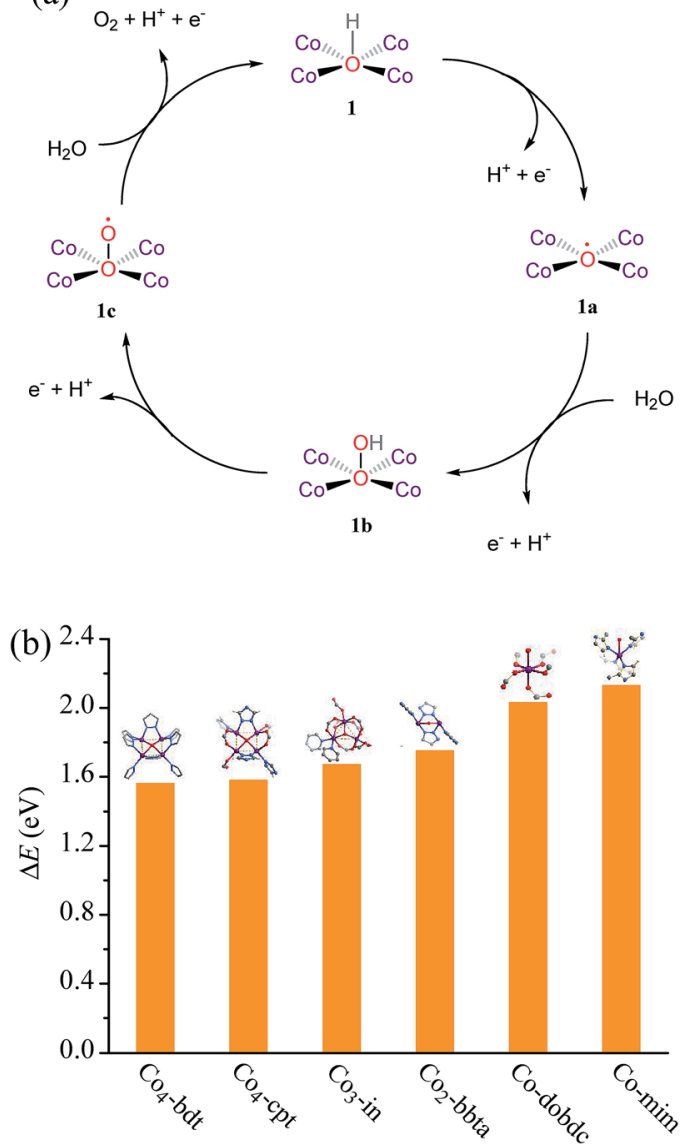

Fig. 4 (a) A proposed reaction mechanism for using $\mathrm{Co}_{4}$-bdt as the catalyst for photodriven water oxidation. (1) The complex 1 is oxidatively activated by the photo-generated hole. (2) The nucleophilic attack of the water molecule forms the $\mathrm{O}-\mathrm{O}$ bond. (3) The complex $1 \mathrm{~b}$ is oxidized to complex 1c. (4) The complex $1 \mathrm{c}$ is further oxidized to evolve $\mathrm{O}_{2}$, accompanied by the regeneration of 1. (b) PDFT calculated adsorption energies of the reacting hydroxyl radical $\left(\Delta E=E\left({ }^{*} \mathrm{OH}\right)-\right.$ $E(*)-\left[E\left(\mathrm{H}_{2} \mathrm{O}\right)-E(\mathrm{H})\right]$, * represents the catalyst).

active site for water oxidation. This phenomenon was also observed for $\mathbf{C o}_{3}$-in and $\mathbf{C o}_{2}$-bbta (Fig. S21†). In other words, the site, capping four coplanar cobalt ions, indeed serves as the
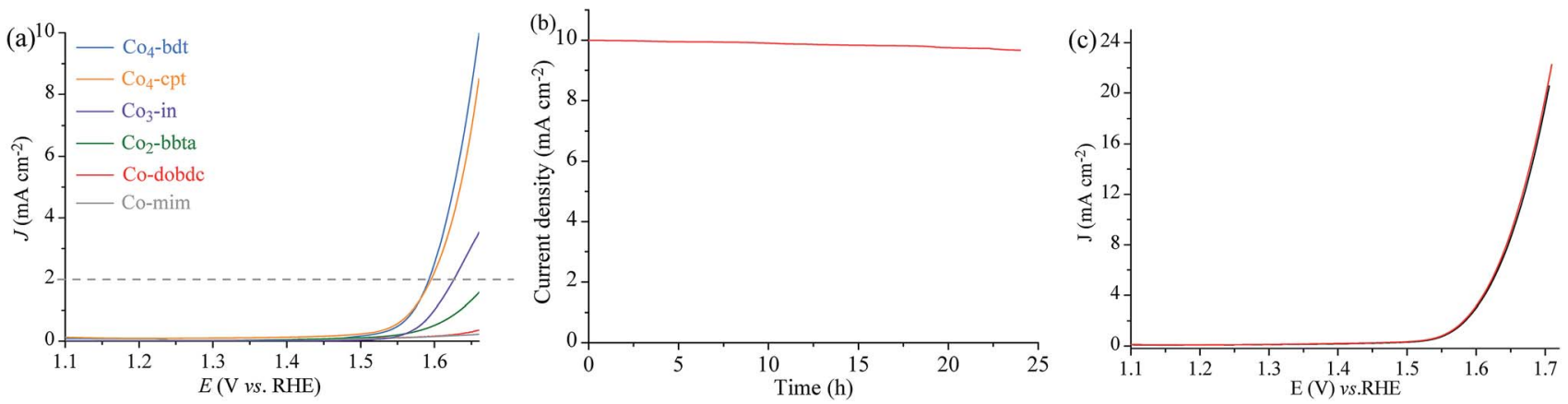

Fig. 3 (a) LSV curves of $\mathrm{Co}_{4}$-bdt, $\mathrm{Co}_{4}$-cpt, $\mathrm{Co}_{3}$-in, $\mathrm{Co}_{2}$-bbta, $\mathrm{Co}$-mim and $\mathrm{Co}$-dobdc at $\mathrm{pH}=7$. (b) The chronopotentiometry curves of $\mathrm{Co}_{4}$-bdt at an overpotential corresponding to the current density of $10 \mathrm{~mA} \mathrm{~cm}^{-2}$ at $\mathrm{pH}=7$. (c) LSV curves of $\mathrm{Co}_{4}$-bdt before (black) and after (red) the electrochemical OER test at $10 \mathrm{~mA} \mathrm{~cm}{ }^{-2}$ for $24 \mathrm{~h}$ at $\mathrm{pH}=7$. 
highly efficient active site for water oxidation. Such an active site for water oxidation is the first to be reported to date. It should be noted that not all oxygen atoms from the $\mathrm{Co}_{4}$ cluster participate in the reaction at the same time, and the $\mathrm{O}$ coordinated on the $\mathrm{Co}_{4}$ cluster will be replaced by the water molecule before the $\mathrm{O}_{2}$ formation. Therefore, although the $\mathrm{O}$ from the $\mathrm{Co}_{4}$ cluster indeed engages in $\mathrm{O}_{2}$ formation, the structure of $\mathbf{C o}_{\mathbf{4}}$-bdt remains during and after the photodriven water oxidation reaction (Fig. 4a, S12 and S24 $\dagger$ ).

To further understand the relationship between the coordination number of the oxygen atom in $\mathrm{OH}^{-}$and the properties, we analyzed the adsorption energy of $\mathrm{OH}^{-}$adsorbed on the active site by periodic density functional theory (PDFT). The adsorption energy $(\Delta E)$ of $\mathrm{OH}^{-}$follows the order, Co-mim (2.13 $\mathrm{eV})>$ Co-dobdc $(2.03 \mathrm{eV})>\mathbf{C o}_{2}$-bbta $(1.75 \mathrm{eV})>\mathbf{C o}_{3}$-in $(1.67 \mathrm{eV})>$ $\mathbf{C o}_{4}$-cpt $(1.58 \mathrm{eV}) \approx \mathbf{C o}_{4}$-bdt $(1.56 \mathrm{eV})>\mathbf{N i}_{\mathbf{4}}$-bdt $(1.19 \mathrm{eV})$ (Fig. 4b), and this implies that the $\mathrm{OH}^{-}$becomes more stable with an increase in the coordination number. The poor performance of $\mathbf{N i}_{\mathbf{4}}$-bdt is due to its too strongly $\mathrm{OH}^{-}$binding. By combining the PDFT simulation results and the isotope tracing experiments, it can be seen that the high catalytic performance of $\mathbf{C o}_{4}$-bdt might be ascribed to the fact that the $\mathrm{OH}^{-}$is appropriately stabilized by four coplanar cobalt ions.

\section{Conclusions}

In conclusion, through a combination of the highly connected cobalt-hydroxide unit and the azolate bridging ligand, we designed and synthesized cobalt azolate frameworks with high stability and excellent water oxidation performance. Since the oxygen atom is simultaneously coordinated by four coplanar cobalt ions, the reacting hydroxyl radical is appropriately stabilized during the water oxidation reaction, promoting the catalytic performance. These results should be insightful for understanding the structure-function relationship of water oxidation catalysts and for developing new MOF-based catalysts.

\section{Conflicts of interest}

There are no conflicts to declare.

\section{Acknowledgements}

This work was supported by the NSFC (21701193, 21890380, and 21821003), the Local Innovative and Research Teams Project of Guangdong Pearl River Talents Program (2017BT01C161), the Guangdong Natural Science Funds for Distinguished Young Scholars (2018B030306009), and the Young Elite Scientists Sponsorship Program by CAST (2017QNRC001). Thank also go to Prof. Jie-Peng Zhang for his valuable suggestions.

\section{Notes and references}

1 J. D. Blakemore, R. H. Crabtree and G. W. Brudvig, Chem. Rev., 2015, 115, 12974-13005.
2 M. D. Kärkäs, O. Verho, E. V. Johnston and B. Åkermark, Chem. Rev., 2014, 114, 11863-12001.

3 X. Yang, Z. Chen, J. Xu, H. Tang, K. Chen and Y. Jiang, ACS Appl. Mater. Interfaces, 2015, 7, 15285-15293.

4 F. Zhang, A. Yamakata, K. Maeda, Y. Moriya, T. Takata, J. Kubota, K. Teshima, S. Oishi and K. Domen, J. Am. Chem. Soc., 2012, 134, 8348-8351.

5 Z.-J. Liu, X.-L. Wang, C. Qin, Z.-M. Zhang, Y.-G. Li, W.-L. Chen and E.-B. Wang, Coord. Chem. Rev., 2016, 313, 94-110.

6 X.-J. Su, M. Gao, L. Jiao, R.-Z. Liao, P. E. M. Siegbahn, J.-P. Cheng and M.-T. Zhang, Angew. Chem., Int. Ed., 2015, 54, 4909-4914.

7 H.-Y. Du, S.-C. Chen, X.-J. Su, L. Jiao and M.-T. Zhang, J. Am. Chem. Soc., 2018, 140, 1557-1565.

8 S. Peng, F. Gong, L. Li, D. Yu, D. Ji, T. Zhang, Z. Hu, Z. Zhang, S. Chou, Y. Du and S. Ramakrishna, J. Am. Chem. Soc., 2018, 140, 13644-13653.

9 X. Wang, H. Xiao, A. Li, Z. Li, S. Liu, Q. Zhang, Y. Gong, L. Zheng, Y. Zhu, C. Chen, D. Wang, Q. Peng, L. Gu, X. Han, J. Li and Y. Li, J. Am. Chem. Soc., 2018, 140, 1533615341.

10 B. Zhang, X. Zheng, O. Voznyy, R. Comin, M. Bajdich, M. García-Melchor, L. Han, J. Xu, M. Liu, L. Zheng, F. P. García de Arquer, C. T. Dinh, F. Fan, M. Yuan, E. Yassitepe, N. Chen, T. Regier, P. Liu, Y. Li, P. De Luna, A. Janmohamed, H. L. Xin, H. Yang, A. Vojvodic and E. H. Sargent, Science, 2016, 352, 333-337.

11 S. Zhao, R. Jin, H. Abroshan, C. Zeng, H. Zhang, S. D. House, E. Gottlieb, H. J. Kim, J. C. Yang and R. Jin, J. Am. Chem. Soc., 2017, 139, 1077-1080.

12 J.-Q. Shen, P.-Q. Liao, D.-D. Zhou, C.-T. He, J.-X. Wu, W.-X. Zhang, J.-P. Zhang and X.-M. Chen, J. Am. Chem. Soc., 2017, 139, 1778-1781.

13 X.-L. Wang, L.-Z. Dong, M. Qiao, Y.-J. Tang, J. Liu, Y. Li, S.-L. Li, J.-X. Su and Y.-Q. Lan, Angew. Chem., Int. Ed., 2018, 57, 9660-9664.

14 W. Tu, Y. Xu, S. Yin and R. Xu, Adv. Mater., 2018, 30, 1707582.

15 D. Li, S.-H. Yu and H.-L. Jiang, Adv. Mater., 2018, 30, 1707377.

16 G. Lan, Y.-Y. Zhu, S. S. Veroneau, Z. Xu, D. Micheroni and W. Lin, J. Am. Chem. Soc., 2018, 140, 5326-5329.

17 S. Pullen, H. Fei, A. Orthaber, S. M. Cohen and S. Ott, J. Am. Chem. Soc., 2013, 135, 16997-17003.

18 N. Kornienko, Y. Zhao, C. S. Kley, C. Zhu, D. Kim, S. Lin, C. J. Chang, O. M. Yaghi and P. Yang, J. Am. Chem. Soc., 2015, 137, 14129-14135.

19 Y. Wang, N.-Y. Huang, J.-Q. Shen, P.-Q. Liao, X.-M. Chen and J.-P. Zhang, J. Am. Chem. Soc., 2018, 140, 38-41.

20 Y. Lee, S. Kim, J. K. Kang and S. M. Cohen, Chem. Commun., 2015, 51, 5735-5738.

21 K. M. Choi, D. Kim, B. Rungtaweevoranit, C. A. Trickett, J. T. D. Barmanbek, A. S. Alshammari, P. Yang and O. M. Yaghi, J. Am. Chem. Soc., 2017, 139, 356-362.

22 M. Ding, R. W. Flaig, H.-L. Jiang and O. M. Yaghi, Chem. Soc. Rev., 2019, 48, 2783-2828. 
23 P.-Q. Liao, J.-Q. Shen and J.-P. Zhang, Coord. Chem. Rev., 2018, 373, 22-48.

24 L. Jiao, Y. Wang, H.-L. Jiang and Q. Xu, Adv. Mater., 2018, 30, 1703663.

25 H. Wang, Q.-L. Zhu, R. Zou and Q. Xu, Chem, 2017, 2, 52-80.

26 L. Chi, Q. Xu, X. Liang, J. Wang and X. Su, Small, 2016, 12, 1351-1358.

27 Q. Xu, H. Li, F. Yue, L. Chi and J. Wang, New J. Chem., 2016, 40, 3032-3035.

28 J.-P. Zhang, Y.-B. Zhang, J.-B. Lin and X.-M. Chen, Chem. Rev., 2012, 112, 1001-1033.

29 K. Wang, X.-L. Lv, D. Feng, J. Li, S. Chen, J. Sun, L. Song, Y. Xie, J.-R. Li and H.-C. Zhou, J. Am. Chem. Soc., 2016, 138, 914-919.

30 X.-L. Lv, K. Wang, B. Wang, J. Su, X. Zou, Y. Xie, J.-R. Li and H.-C. Zhou, J. Am. Chem. Soc., 2017, 139, 211-217.

31 N. M. Padial, E. Q. Procopio, C. Montoro, E. López, J. E. Oltra, V. Colombo, A. Maspero, N. Masciocchi, S. Galli, I. Senkovska, S. Kaskel, E. Barea and J. A. R. Navarro, Angew. Chem., 2013, 125, 8448-8452.

32 X.-F. Lu, P.-Q. Liao, J.-W. Wang, J.-X. Wu, X.-W. Chen, C.-T. He, J.-P. Zhang, G.-R. Li and X.-M. Chen, J. Am. Chem. Soc., 2016, 138, 8336-8339.

33 H. J. Choi, M. Dinca, A. Dailly and J. R. Long, Energy Environ. Sci., 2010, 3, 117-123.

34 D. Hong, Y. Yamada, T. Nagatomi, Y. Takai and S. Fukuzumi, J. Am. Chem. Soc., 2012, 134, 19572-19575.

35 F. A. Frame, T. K. Townsend, R. L. Chamousis, E. M. Sabio, T. Dittrich, N. D. Browning and F. E. Osterloh, J. Am. Chem. Soc., 2011, 133, 7264-7267.

36 D. M. Robinson, Y. B. Go, M. Mui, G. Gardner, Z. Zhang, D. Mastrogiovanni, E. Garfunkel, J. Li, M. Greenblatt and G. C. Dismukes, J. Am. Chem. Soc., 2013, 135, 3494-3501.

37 X. Du, Y. Ding, R. Xiang and X. Xiang, Phys. Chem. Chem. Phys., 2015, 17, 10648-10655.

38 Y. Zhao, Y. Zhang, Y. Ding and M. Chen, Dalton Trans., 2015, 44, 15628-15635.

39 Y. Yamada, K. Oyama, R. Gates and S. Fukuzumi, Angew. Chem., Int. Ed., 2015, 54, 5613-5617.

40 N. S. McCool, D. M. Robinson, J. E. Sheats and G. C. Dismukes, J. Am. Chem. Soc., 2011, 133, 11446-11449.
41 S. Berardi, G. La Ganga, M. Natali, I. Bazzan, F. Puntoriero, A. Sartorel, F. Scandola, S. Campagna and M. Bonchio, J. Am. Chem. Soc., 2012, 134, 11104-11107.

42 X.-B. Han, Z.-M. Zhang, T. Zhang, Y.-G. Li, W. Lin, W. You, Z.-M. Su and E.-B. Wang, J. Am. Chem. Soc., 2014, 136, 5359-5366.

43 X.-B. Han, Y.-G. Li, Z.-M. Zhang, H.-Q. Tan, Y. Lu and E.-B. Wang, J. Am. Chem. Soc., 2015, 137, 5486-5493.

44 H. Lv, J. Song, Y. V. Geletii, J. W. Vickers, J. M. Sumliner, D. G. Musaev, P. Kögerler, P. F. Zhuk, J. Bacsa, G. Zhu and C. L. Hill, J. Am. Chem. Soc., 2014, 136, 9268-9271.

45 M. Natali, M. Orlandi, S. Berardi, S. Campagna, M. Bonchio, A. Sartorel and F. Scandola, Inorg. Chem., 2012, 51, 73247331.

46 P. D. Frischmann, K. Mahata and F. Würthner, Chem. Soc. Rev., 2013, 42, 1847-1870.

47 B. Das, B.-L. Lee, E. A. Karlsson, T. Åkermark, A. Shatskiy, S. Demeshko, R.-Z. Liao, T. M. Laine, M. Haukka, E. Zeglio, A. F. Abdel-Magied, P. E. M. Siegbahn, F. Meyer, M. D. Kärkäs, E. V. Johnston, E. Nordlander and B. Åkermark, Dalton Trans., 2016, 45, 13289-13293.

48 A. F. Abdel-Magied, W. A. A. Arafa, T. M. Laine, A. Shatskiy, M. D. Kärkäs, B. Åkermark and E. V. Johnston, ChemCatChem, 2017, 9, 1583-1587.

49 J. W. Vickers, J. M. Sumliner, H. Lv, M. Morris, Y. V. Geletii and C. L. Hill, Phys. Chem. Chem. Phys., 2014, 16, 1194211949.

50 M. D. Kärkäs, Y.-Y. Li, P. E. M. Siegbahn, R.-Z. Liao and B. Åkermark, Inorg. Chem., 2018, 57, 10881-10895.

51 Y. Xu, A. Fischer, L. Duan, L. Tong, E. Gabrielsson, B. Åkermark and L. Sun, Angew. Chem., Int. Ed., 2010, 122, 9118-9121.

52 R. J. Holmberg, M. Kay, I. Korobkov, E. Kadantsev, P. G. Boyd, T. Aharen, S. Desgreniers, T. K. Woo and M. Murugesu, Chem. Commun., 2014, 50, 5333-5335.

53 Z. Li, L. Du, J. Zhou, L. Li, Y. Hu, Y. Qiao, M. Xie and Q. Zhao, New J. Chem., 2013, 37, 2473-2478.

54 P. D. C. Dietzel, Y. Morita, R. Blom and H. Fjellvåg, Angew. Chem., 2005, 117, 6512-6516.

55 R. Banerjee, A. Phan, B. Wang, C. Knobler, H. Furukawa, M. O'Keeffe and O. M. Yaghi, Science, 2008, 319, 939-943. 